\title{
Continuous Flow Isotope Ratio Mass Spectrometry of Carbon Dioxide Trapped as Strontium Carbonate
}

\author{
D. Harris, ${ }^{\mathrm{a}, \mathrm{l}}$ L. K. Porter, ${ }^{\mathrm{b}}$ and E. A. Paul ${ }^{\mathrm{a}}$ \\ a Department of Crop and Soil Sciences, Michigan State University, East \\ Lansing, MI 48824 \\ ${ }^{b} U S D A-A R S-N R R C-N P A, 301$ S. Howes \#407, Fort Collins, CO 80521
}

\begin{abstract}
The isotopic signal provided by differential discrimination against atmospheric carbon dioxide $\left({ }^{13} \mathrm{CO}_{2}\right)$ by $\mathrm{C}_{3}$ and $\mathrm{C}_{4}$ plant photosynthetic pathways is being widely used to study the processes of carbon $(C)$ fixation, soil organic matter formation, and mineralization in nature. These studies have been facilitated by the availability of automated $\mathrm{C}$ and nitrogen $(\mathrm{N})$ combustion analyzers (ANCA) combined with continuous flow isotope ratio mass spectrometers (CFIRMS). Analysis of ${ }^{13} \mathrm{CO}_{2}$ in these instruments requires consistent sample mass for best precision, a requirement that is easily satisfied for soil and tissue samples by adjusting sample weight. Consistent $\mathrm{CO}_{2}$ sample size is much more difficult to achieve using gas handling systems for samples of headspace gases when $\mathrm{CO}_{2}$ concentrations vary widely. Long storage of gaseous samples also is difficult. Extended respiration studies are most easily conducted by trapping $\mathrm{CO}_{2}$ in alkali and conversion to an insoluble carbonate. Thermal decomposition of the carbonate in an on-line ANCA allows consistent and optimal $\mathrm{CO}_{2}$ sample mass to be obtained. The use of precipitated
\end{abstract}

'Corresponding author (e-mail address: 22833mgr@msu.edu). 
carbonates also facilitates storage of samples and enables full automation of sample analysis using an ANCA interfaced to a CFIRMS. Calcium $(\mathrm{Ca})$, strontium (Sr), and barium (Ba) carbonates were tested. Strontium carbonate $\left(\mathrm{SrCO}_{3}\right)$ with the addition of vanadium pentoxide $\left(\mathrm{V}_{2} \mathrm{O}_{5}\right)$ as a combustion catalyst was found most suitable.

\section{INTRODUCTION}

Differential discrimination against ${ }^{13} \mathrm{CO}_{2}$ by the $\mathrm{C}_{3}$ and $\mathrm{C}_{4}$ pathways of photosynthesis results in differences of $10-15 \%$ in the ${ }^{13} \mathrm{C}$ content of the plant biomass formed. This isotopic signal is altered only slightly and reasonably predictably during plant residue composition and humification (Balesdent et al., 1993; Wedin et al., 1995; Ågren et al., 1996). It provides an excellent tracer to measure soil organic matter formation and decomposition in systems where the proportion of $\mathrm{C}_{3}$ and $\mathrm{C}_{4}$ plants has changed (Balesdent et al., 1988; Balesdent and Balabane, 1992; Bonde et al., 1992; Ryan and Aravena, 1994). The combination of automated sample combustion systems (ANCA), which convert solid samples to $\mathrm{CO}_{2}$ and on-line continuous flow isotope ratio mass spectrometers (CFIRMS), has greatly expanded the possibilities for ${ }^{13} \mathrm{C}$ research because of increased sample throughput at modest cost (Barrie and Prosser, 1996). The ANCA-CFIRMS instruments are capable of achieving a precision $( \pm 0.1 \%)$ adequate for many studies of ${ }^{13} \mathrm{C}$ natural abundance.

An important component of ${ }^{13} \mathrm{C}$ studies is the ability to measure the ${ }^{13} \mathrm{C}$ content of $\mathrm{CO}_{2}$ evolved during microbial decomposition. Collection, storage, and direct analysis of ${ }^{13} \mathrm{CO}_{2}$ in headspace or soil atmosphere samples is feasible but has serious disadvantages where many samples are needed over long periods. The recent commercial availability of a sample preparation system which uses thermally controlled adsorption and desorption to concentrate $\mathrm{CO}_{2}$ from air samples solves some of these problems, but is, as yet, available only in a few laboratories (Brooks et al., 1993). A further problem with direct analysis of ${ }^{13} \mathrm{CO}_{2}$ from gas samples in a CFIRMS is abundance sensitivity which is the variation in the measured isotope ratio with ion beam intensity or sample size. This is due to increased scatter of the major ion beam $(\mathrm{m} / \mathrm{z} 44)$ into the adjacent minor ion collector $(\mathrm{m} / \mathrm{z} 45)$ as ion beam intensity increases with higher pressure of $\mathrm{CO}_{2}$ in the ion source. Dual inlet mass spectrometers overcome this problem by varying the volumes of the inlet chambers to equalize ion beam intensities derived from the standard and sample. Such equalization is not possible in a single inlet CFIRMS where standards and samples are analyzed separately. The consequence of this source of error for CFIRMS measurements of ${ }^{13} \mathrm{CO}_{2}$ is that gas samples and calibration standards are best adjusted to contain similar masses of $\mathrm{C}$ prior to their introduction to the instrument.

Essentially all the $\mathrm{CO}_{2}$ can be collected from the headspace of an incubation container or a field canopy over a wide range of time intervals, sampling volumes, 
and $\mathrm{CO}_{2}$ concentrations using simple, inexpensive equipment. The precipitation of carbonate and titration of excess $\mathrm{OH}^{-}$is a widely used method for measuring total $\mathrm{CO}_{2}$ production by microbial respiration (Zibilske, 1994). Precipitated carbonate can be separated and dried and is easily weighed to a consistent mass without contamination from atmospheric $\mathrm{CO}_{2}$.

In the past, measurements of ${ }^{13} \mathrm{C}$ in carbonates have been made by releasing $\mathrm{CO}_{2}$ with phosphoric acid $\left(\mathrm{H}_{3} \mathrm{PO}_{4}\right)$ and then transferring the $\mathrm{CO}_{2}$ via cold traps to a conventional 'batch fed' mass spectrometer (Boutton, 1991). We have developed an alternative method where $\mathrm{CO}_{2}$ is released from $\mathrm{SrCO}_{3}$ by thermal decomposition in an ANCA. The ANCA forms the sample preparation stage of a CFIRMS. Thus, the analysis of ${ }^{13} \mathrm{CO}_{2}$ trapped as carbonate can be performed using the same equipment that is used for total $\mathrm{C}$ and ${ }^{13} \mathrm{C}$ analysis of plant, soil, and other biological samples. The method satisfies the important criteria of giving quantitative release of $\mathrm{CO}_{2}$ from $\mathrm{SrCO}_{3}$ with no measurable isotopic discrimination.

\section{MATERIALS AND METHODS}

\section{${ }^{13} \mathrm{C}$ Analysis of Carbonates}

Samples of $\mathrm{Ca}, \mathrm{Sr}$, and $\mathrm{Ba}$ carbonates containing $200 \mu \mathrm{g} \mathrm{C}$ were weighed into tin capsules $(8 \times 5 \mathrm{~mm}$, weighing approx. $30 \mathrm{mg})$. Vanadium pentoxide $(5 \mathrm{mg})$ was added to some samples as a catalyst to enhance the combustion of the tin capsule. The samples were analyzed for total $\mathrm{C}$ and ${ }^{13} \mathrm{C}$ in an ANCA-CFIRMS using a Europa Scientific Roboprep CN Analyzer and 20/20 mass spectrometer (Europa Scientific, Inc., Franklin, $\mathrm{OH}$ ). Thermal decomposition of the carbonates was achieved in the combustion tube of the ANCA heated to $1,020^{\circ} \mathrm{C}$. With a pulse of oxygen $\left(\mathrm{O}_{2}\right)(10 \mathrm{~mL})$ and in the presence of $\mathrm{V}_{2} \mathrm{O}_{5}$, flash combustion of the tin sample capsule produces a transient local temperature of about $1,700^{\circ} \mathrm{C}$ (Kirsten, 1983). Thermal decomposition of calcium carbonate $\left(\mathrm{CaCO}_{3}\right)$ occurs at $830^{\circ} \mathrm{C}$, strontium carbonate $\left(\mathrm{SrCO}_{3}\right)$ at $1,100^{\circ} \mathrm{C}$, while barium carbonate $\left(\mathrm{BaCO}_{3}\right)$ is more stable, decomposing at $1,300^{\circ} \mathrm{C}$ (Weast, 1973). Ash was removed from the combustion tube by suction after each analytical run of 64 samples.

We compared measurements of ${ }^{13} \mathrm{CO}_{2}$ obtained by thermal decomposition with surements on $\mathrm{CO}_{2}$ gas obtained by acid treatment of $\mathrm{CaCO}_{3}, \mathrm{SrCO}_{3}$, and $\mathrm{BaCO}_{3}$. Aliquots of $\mathrm{CaCO}_{3}(0.68 \mathrm{~g}), \mathrm{SrCO}_{3}(10 \mathrm{~g})$, and $\mathrm{BaCO}_{3}(1.34 \mathrm{~g})$ were placed in 160 -mL serum bottles which were closed with butyl rubber septa (Geo-Microbial Technologies, Ochatalata, OK). The bottles were evacuated and flushed twice with helium (He) then re-evacuated to $50 \mathrm{~Pa}$. The $\mathrm{CO}_{2}$ was released from the carbonates by adding $20 \mathrm{~mL} 40 \%$ phosphoric acid $\left(\mathrm{H}_{3} \mathrm{PO}_{4}\right)$ from a syringe and shaking the bottles on a rotary shaker $(200 \mathrm{rpm})$ for $1 \mathrm{~h}$ after which no visible carbonate remained. The carbonate aliquots were calculated to produce an over pressure of $\mathrm{CO}_{2}$ in the bottles which could then be sampled without contamination by mass flow of air into the syringe. 
An injection port was fitted in the carrier gas line $\left(\mathrm{He} 60 \mathrm{~mL} \cdot \mathrm{min}^{-1}\right)$ before the water trap and chromatography column of the $\mathrm{CN}$ analyzer. Manual $\mathrm{CO}_{2}$ injection $(400 \mu \mathrm{L})$ from a syringe was timed to occur $60 \mathrm{sec}$ after the beginning of the automatic analytical sequence the instrument. Under these conditions, the $\mathrm{CO}_{2}$ peak from the gas injection arrived at the inlet of the mass spectrometer at the same point in the analytical cycle as would $\mathrm{CO}_{2}$ derived from solid samples combusted by the normal operation of the ANCA. This allowed $\mathrm{CO}_{2}$ from gas or from solid carbonate samples to be analyzed in succession, using the same reference standards for ${ }^{13} \mathrm{C}$, by placing empty tin capsules in the autosampler at positions in the sample sequence when gas samples were to be introduced. The working standard was beet sucrose containing $200 \mu \mathrm{g} \mathrm{C}$ at $-25.63 \%$ VPDB.

We also tested the accuracy of measurement of ${ }^{13} \mathrm{CO}_{2}$ after thermal decomposition international standard $\mathrm{CaCO}_{3}$ (NBS 19, SRM 8544,+1.95\% VPBD) in the ANCA by comparison with standard sucrose (ANU sucrose, SRM 8542, $10.47 \%$ VPDB). This comparison was made without the addition of $\mathrm{V}_{2} \mathrm{O}_{5}$ to the carbonate samples.

\section{Titration of Hydroxide After Precipitation of Carbonate}

Titration of excess hydroxide $(\mathrm{OH})$ in the base traps after exposure to $\mathrm{CO}_{2}$ measures the total $\mathrm{CO}_{2}$ trapped and also neutralizes the remaining $\mathrm{OH}$; preventing further absorption of $\mathrm{CO}_{2}$. Barium chloride $\left(\mathrm{BaCl}_{2}\right)$ is normally added to precipitate carbonate as $\mathrm{BaCO}_{3}$ from base traps before titration residual $\mathrm{OH}$. Its suitability for this purpose is based on the low solubility of $\mathrm{BaCO}_{3}(0.1 \mathrm{mM})$ and relatively high solubility of $\mathrm{Ba}(\mathrm{OH})_{2}(0.2 \mathrm{M})$. However, the high thermal stability of $\mathrm{BaCO}_{3}$ limits its decomposition in the ANCA. Therefore, we tested $\mathrm{Ca}$ and $\mathrm{Sr}$ chlorides as alternatives for precipitation of carbonate and for effects on the titration of residual $\mathrm{OH}$. Both $\mathrm{CaCO}_{3}$ and $\mathrm{SrCO}_{3}$ are less soluble in water than $\mathrm{BaCO}_{3}$, but their hydroxides are also less soluble than $\mathrm{Ba}(\mathrm{OH})_{2}(34$ and $25 \mathrm{mM}$, respectively). The relatively low solubility of these hydroxides may lead to their precipitation on addition of $\mathrm{CaCl}_{2}$ or $\mathrm{SrCl}_{2}$ to base traps. Hydroxide precipitates may cause problems in the subsequent titration.

Carbonate in aliquots $(2 \mathrm{~mL})$ of a solution which simulated a soil respiration base trap [1.25M sodium hydroxide $(\mathrm{NaOH})+0.5 \mathrm{M}$ sodium carbonate $\left.\left(\mathrm{Na}_{2} \mathrm{CO}_{3}\right)\right]$ was precipitated by adding $1 \mathrm{~mL} 2 \mathrm{M}$ calcium chloride $\left(\mathrm{CaCl}_{2}\right)$ or strontium chloride $\left(\mathrm{SrCl}_{2}\right)$. Water $(3 \mathrm{~mL})$ was added to increase the volume sufficiently to cover the semi-micro combination electrode. The suspension was titrated to $\mathrm{pH} 7.0$ with $0.3 \mathrm{M}$ hydrochloric acid $(\mathrm{HCl})$ delivered by automatic titrator (Schott, Yonkers, $\mathrm{NY}$ ). The titrator was set to deliver $\mathrm{HCl}$ at $4 \mathrm{~mL} \cdot \mathrm{min}^{-1}$ until $\mathrm{pH} 10.0$ when the delivery rate slowed in proportion to the difference between $\mathrm{pH}$ and the endpoint.

\section{Evaluation of the Collection and Measurement of ${ }^{13} \mathrm{CO}_{2}$ as Carbonate}

Two possible sources of error in the $\delta{ }^{13} \mathrm{C}$ measurement are incomplete decomposition of the carbonate in the ANCA and contamination with $\mathrm{C}$ from 
other sources, such as the atmosphere. Incomplete decomposition would lead to carry-over of $\mathrm{CO}_{2}$ between samples because residual carbonate would remain in the combustion tube of the ANCA to be released by the combustion of subsequent sample packages. Contamination of the carbonate can result from impurity in the $\mathrm{NaOH}$ used to trap $\mathrm{CO}_{2}$, from other reagents, or the atmosphere during handling and titration of the base trap. These sources of contamination can be minimized by precautions in sample preparation and handling but can not be completely eliminated in laboratory incubation or field experiments. However, the magnitude of the contamination can be measured by isotope dilution after adding known quantities of $\mathrm{CO}_{2}$ or carbonate of known isotopic composition to blank base traps. The $\delta{ }^{13} \mathrm{C}$ of the mixture is defined by the following equation:

$$
\mathrm{M}=\mathrm{xA}+\mathrm{yB} /(\mathrm{x}+\mathrm{y})
$$

where: $\mathrm{M}$ is the $\delta^{13} \mathrm{C}$ of the carbonate sample, $\mathrm{x}$ is the mass of contaminant $\mathrm{C}, \mathrm{A}$ is $\delta{ }^{13} \mathrm{C}$ of the contaminant $\mathrm{C}, \mathrm{y}$ is the mass of $\mathrm{C}$ in the standard addition, and $\mathrm{B}$ is the $\delta{ }^{13} \mathrm{Cof}$ the standard addition. Because Equation [1] contains two unknowns, $\mathrm{x}$ and $\mathrm{A}$, it can not be solved for a single set of the known values $\mathrm{M}, \mathrm{y}$, and $\mathrm{B}$. However, if several measurements of base traps with different standard additions are made, $\mathrm{x}$ and $\mathrm{A}$ can be estimated numerically. These values can then be used in the following equation to correct measured $\delta{ }^{13} \mathrm{C}$ values provided that the carbonate preparation procedures remain unchanged.

$$
\mathbf{G}=\frac{\mathrm{M}(\mathrm{x}+\mathrm{y})-\mathbf{A x}}{\mathrm{y}}
$$

where: $\mathrm{G}$ is the corrected $\delta^{13} \mathrm{C}$ of the sample and $\mathrm{y}$ is the mass of $\mathrm{C}$ determined by titration from the difference between sample and blank titre.

We estimated the mass and $\delta{ }^{13} \mathrm{C}$ of base trap contamination using a series of control base traps ( $2 \mathrm{~mL} 2.5 \mathrm{M} \mathrm{NaOH}$ in $20-\mathrm{mL}$ glass vials) placed in $1-\mathrm{L}$ canning jars fitted with rubber septa. The $\mathrm{NaOH}$ solution was prepared without special precautions to eliminate ${ }^{13} \mathrm{CO}_{2}$. Aliquots $(0,5,10,15,20$, and $30 \mathrm{~mL})$ of $\mathrm{CO}_{2}$ from a cylinder were added using a syringe. The $\delta{ }^{13} \mathrm{C}$ of the cylinder gas $(-48.46 \%$ VPDB) differed greatly from atmospheric $\mathrm{CO}_{2}$ (about $-7.8 \%$ ), the most likely source of contamination. After $24 \mathrm{~h}$ incubation at $25^{\circ} \mathrm{C}$, the base traps were removed, $1 \mathrm{~mL} 2 \mathrm{M} \mathrm{SrCl}_{2}$ was added and the suspension titrated to $\mathrm{pH} 7$ with $\mathrm{HCl}$ under room air. The $\mathrm{SrCO}_{3}$ was washed twice with water by centrifugation ( 270 $\mathrm{g}, 5 \mathrm{~min}$ ) and dried at $60^{\circ} \mathrm{C}$. The dried pellets of $\mathrm{SrCO}_{3}$ were crushed with a spatula and samples $\left(2.4 \mathrm{mg}\right.$ ) were weighed into tin capsules, and $\mathrm{V}_{2} \mathrm{O}_{5}(5 \mathrm{mg})$ added. The $\mathrm{SrCO}_{3}$ samples were analyzed for ${ }^{13} \mathrm{C}$ in the ANCA-CFIRMS and the measured $\delta{ }^{13} \mathrm{C}$ values used to estimate the mass $(\mathrm{x})$ and $\delta{ }^{13} \mathrm{C}(\mathrm{A})$ of base trap contamination. The estimates were computed by minimizing the sum of squares of the differences between measured and calculated $\delta{ }^{13} \mathrm{C}$ values according to Equation [1] using the 'Solver' function of Microsoft Excel 5.0 spreadsheet software (Microsoft, Seattle, WA). 

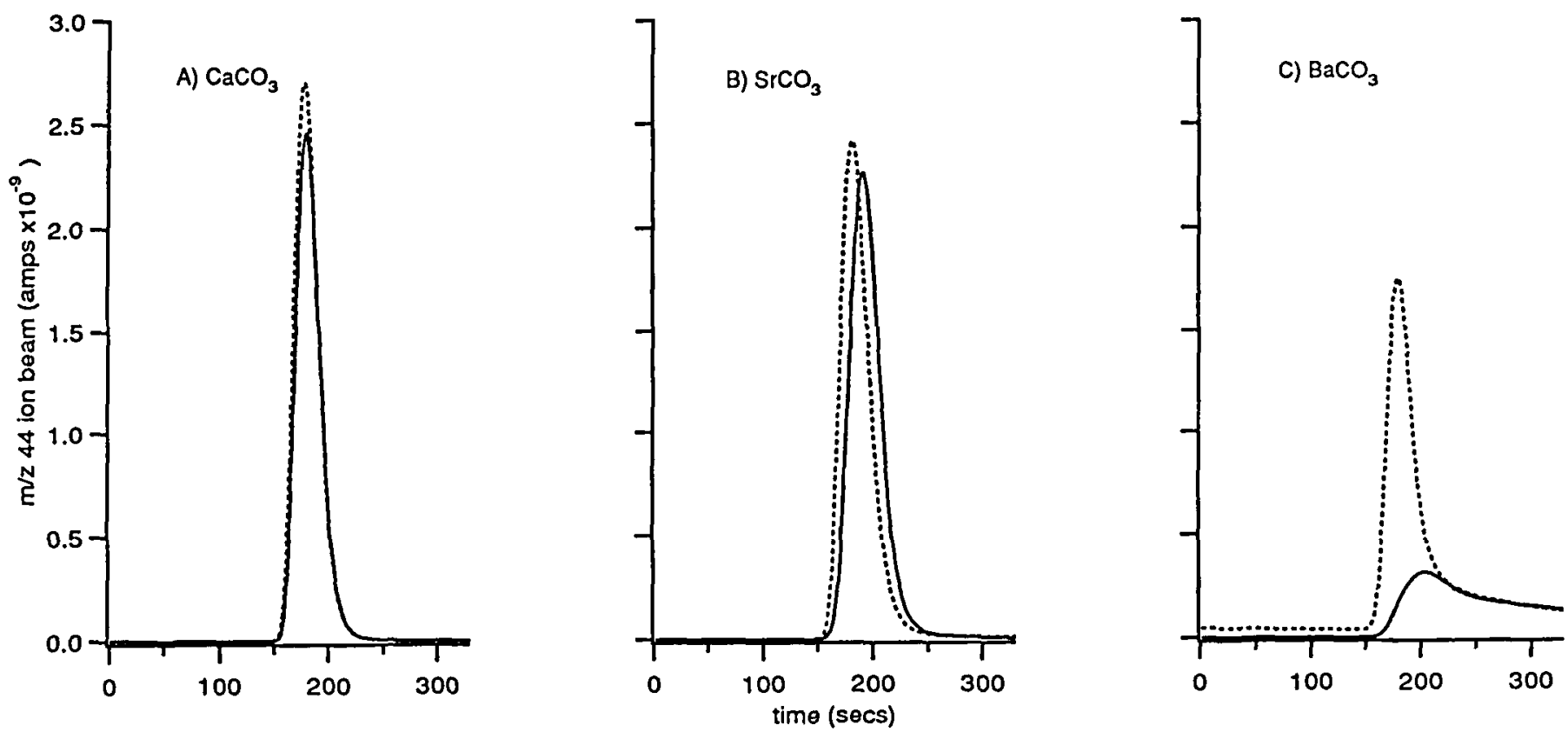

FIGURE 1. Effect of adding $\mathrm{V}_{2} \mathrm{O}_{5}$ to carbonates on release of $\mathrm{CO}_{2}$ in ANCA: A) $\left.\mathrm{CaCO}_{3}, \mathrm{~B}\right) \mathrm{SrCO}_{3}$, and C) $\mathrm{BaCO}_{3}$, - carbonate alone, --carbonate $+\mathrm{V}_{2} \mathrm{O}_{3}$. 


\section{RESULTS AND DISCUSSION}

\section{${ }^{13} \mathrm{C}$ Analysis of Carbonates}

The ANCA gave a symmetrical $\mathrm{CO}_{2}$ peak shape and quantitative recovery of $\mathrm{CO}_{2}$ from $\mathrm{CaCO}_{3}$ and $\mathrm{SrCO}_{3}$ when the combustion tube packing was in perfect condition (Figure 1a,b). However, degradation in the performance of the combustion tube with age or ash accumulation led to $\mathrm{CO}_{2}$ peak tailing and incomplete recovery of $\mathrm{C}$ from $\mathrm{SrCO}_{3}$ (data not hown). The addition of $\mathrm{V}_{2} \mathrm{O}_{5}$ made the system relatively immune to performance degradation, presumably by increasing the flash combustion temperature of the sample capsule. Severe peak tailing was observed with $\mathrm{BaCO}_{3}$ with or without the addition of $\mathrm{V}_{2} \mathrm{O}_{5}$ (Figure 1c).

Quantitative recovery of $\mathrm{CO}_{2}$ from $\mathrm{CaCO}_{3}$ and $\mathrm{SrCO}_{3}$ by thermal decomposition was achieved, but recovery from $\mathrm{BaCO}_{3}$ was incomplete and variable (70-98\%). Measurements of ${ }^{13} \mathrm{CO}_{2}$ after thermal decomposition gave results which did not differ significantly from measurements made on $\mathrm{CO}_{2}$ released from the same materials by acid treatment (Table 1). However, the variability in $\delta{ }^{13} \mathrm{C}$ was greater when $\mathrm{BaCO}_{3}$ was decomposed in the ANCA compared to either acid release or thermal decomposition of $\mathrm{CaCO}_{3}$ or $\mathrm{SrCO}_{3}$. Calcium carbonate was most easily decomposed of the three carbonates and did not require the addition of $\mathrm{V}_{2} \mathrm{O}_{5}$ to ensure complete conversion to $\mathrm{CO}_{2}$. The $\delta{ }^{13} \mathrm{C}$ content of $\mathrm{NBS} 19 \mathrm{CaCO}_{3}$ was measured as $+2.01 \%$ SD $0.06(n=4)$ which is not significantly different from the international consensus value of $+1.95 \%$ VPDB.

\section{Titration of Hydroxide After Precipitation of Carbonate}

Addition of $\mathrm{CaCl}_{2}$ to the base trap solution resulted in the precipitation of a complex $\mathrm{CaCO}_{3}$ and $\mathrm{Ca}(\mathrm{OH})_{2}$ or $\mathrm{CaO}$. The hydroxide slowly redissolved as the

TABLE 1. Release of $\mathrm{CO}_{2}$ from carbonates by thermal decomposition in an ANCA and its effect on CFIRMS measurement of $\delta{ }^{13} \mathrm{CO}_{2}$ compared to $\mathrm{CO}_{2}$ liberated by acid treatment.

\begin{tabular}{|l|rr|rr|rr|}
\hline \multirow{3}{*}{$\begin{array}{c}\text { Carbonate } \\
\text { Source }\end{array}$} & \multicolumn{5}{|c|}{ Decomposition } \\
\cline { 2 - 7 } & \multicolumn{4}{|c|}{ Thermal } & \multicolumn{2}{c|}{ Acid } \\
\cline { 2 - 7 } & \multicolumn{4}{|c|}{ Total C (\%) \pm SD } & $\delta^{13} \mathrm{C}(\%) \pm$ SD & \multicolumn{2}{|c|}{${ }^{13} \mathrm{C}(\%) \pm$ SD } \\
\hline $\mathrm{CaCO}_{3}$ & 99.82 & 0.24 & -38.69 & 0.06 & -38.71 & 0.09 \\
$\mathrm{SrCO}_{3}$ & 100.14 & 0.75 & -13.59 & 0.10 & -13.63 & 0.07 \\
$\mathrm{BaCO}_{3}$ & 85.49 & 10.88 & -22.47 & 0.28 & -22.68 & 0.07 \\
\hline
\end{tabular}

*\% theoretical, $n=4$. 


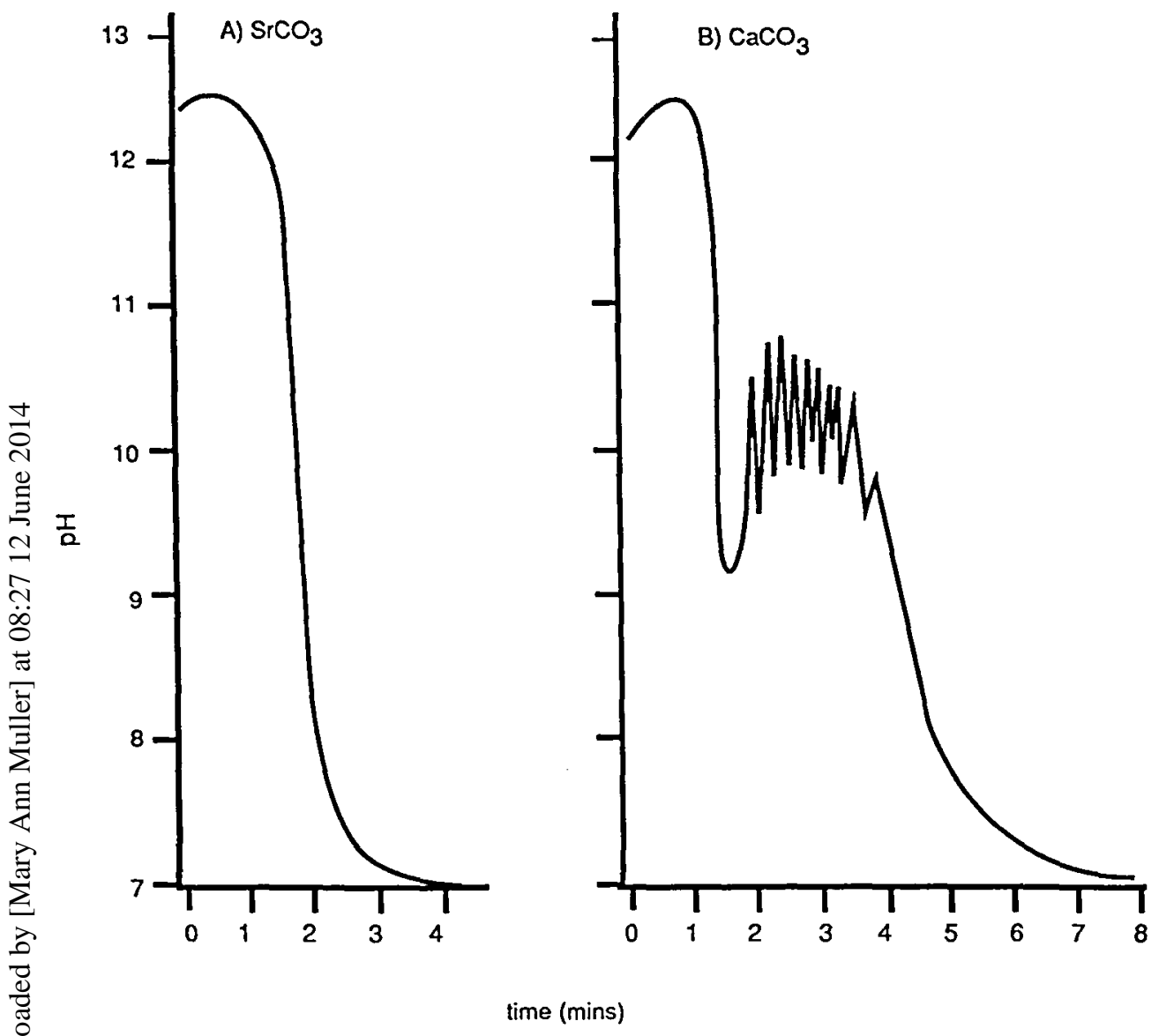

FIGURE 2. Titration curves for simulated base traps after $\mathrm{CO}_{3}$ precipitation with $\mathrm{A}$ ) $\mathrm{SrCl}_{2}$ and $\mathrm{B}$ ) $\mathrm{CaCl}_{2}$. The $0.3 \mathrm{M} \mathrm{HCl}$ was added at $4 \mathrm{~mL} \mathrm{~min}^{-1}$ until $\mathrm{pH} 10$, when delivery rate slowed in proportion to the distance from the $\mathrm{pH} 7.0$ endpoint.

pH decreased during titration. This produced complex titration curves (Figure 2b) with $\mathrm{pH}$ oscillations due interaction between $\mathrm{OH}^{-}$dissolution and the endpoint approach algorithm of the titrator. The endpoint could be accurately obtained but the time taken by the automatic titrator to complete the titration was unpredictable and much longer than for the $\mathrm{Sr}$ system. The precipitate from the $\mathrm{Ca}$ system coated glassware, particularly the $\mathrm{pH}$ electrode, requiring frequent acid treatment for removal. Similar precipitates were observed with $\mathrm{SrCl}_{2}$ when the concentration 


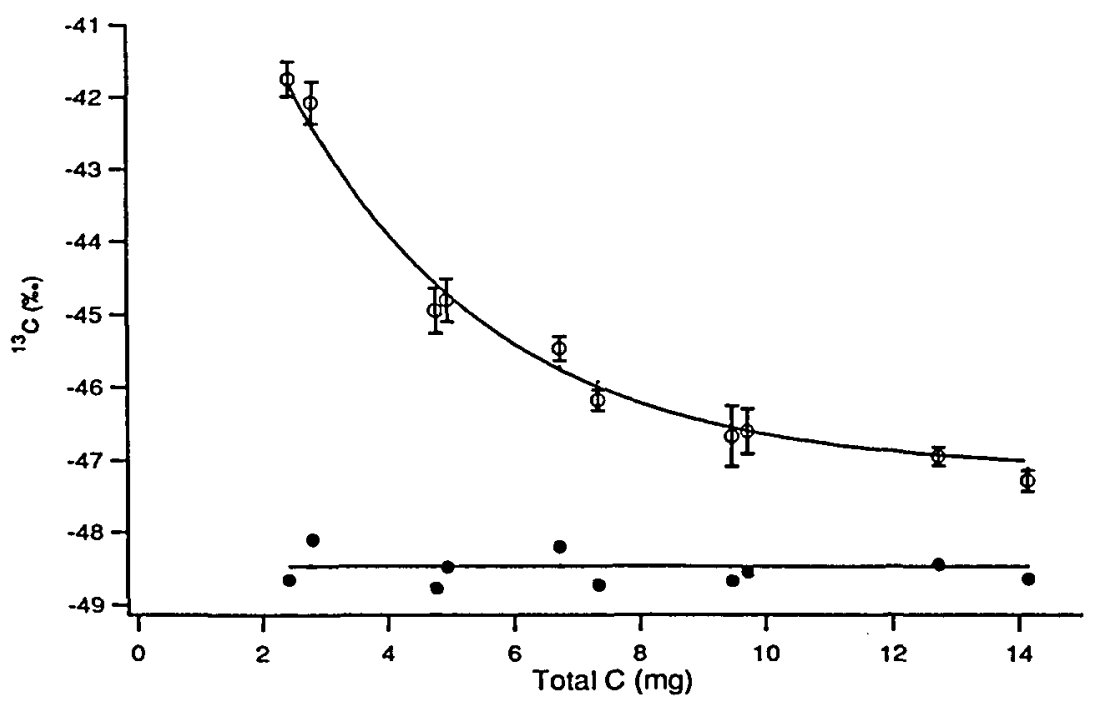

FIGURE 3. Measured and corrected $\delta{ }^{13} \mathrm{C}$ values for $\mathrm{CO}_{2}$ added to canning jars after trapping $2.5 \mathrm{M} \mathrm{NaOH}$ and precipitation as $\mathrm{SrCO}_{3}$. Open circles represent means and standard deviations of 4 replicate jars, the curve represents the model $M=x A+y B /(x+y)$. Filled circles are corrected $\delta^{13} \mathrm{C}$ values using fitted values of $x$ and $A$ calculated from $G=[(x+y) M$ $\mathrm{xA}] / \mathrm{y}$, where $\mathrm{M}$ is the measured $\delta{ }^{13} \mathrm{C}, \mathrm{G}$ the corrected $\delta{ }^{13} \mathrm{C}, \mathrm{x}$ and $\mathrm{y}$ are the masses of contaminant and added $\mathrm{C}, \mathrm{A}$, and $\mathrm{B}$ are the $\delta{ }^{13} \mathrm{C}$ values of the contaminant and added $\mathrm{C}$, respectively.

of $\mathrm{OH}^{-}$was high (2M), but these precipitates redissolved during the titration without the complex behavior observed with $\mathrm{CaCl}_{2}$ (Figure 2a). Strontium carbonate formed a fine granular precipitate which did not adhere strongly to glassware.

\section{Estimation of Carbon from Extraneous Sources}

The $\delta{ }^{13} \mathrm{C}$ values of the $\mathrm{SrCO}_{3}$ recovered from base traps after standard additions of $\mathrm{CO}_{2}$ were enriched in ${ }^{13} \mathrm{C}$ compared to the original cylinder gas indicating contamination with $\mathrm{C}$ from a less depleted source. The data and fitted model (Equation [1]) are shown in Figure 3. The mass of $\mathrm{C}$ derived from contaminants (x), is estimated as $0.44 \mathrm{mg}$ and its $\delta{ }^{13} \mathrm{C}(\mathrm{A})$ as $-3.87 \%$. About $40 \%$ of this $\mathrm{C}$ (approx. $0.18 \mathrm{mg}$ ) was present in the original atmosphere of the $1-\mathrm{L}$ canning jar. The estimates can be used to correct the measured $\delta{ }^{13} \mathrm{C}$ values using Equation [2]. Here, for illustration, the correction is applied to the standards from which its parameters were derived (Figure 3 ). The corrected measurements (mean 48.52\% $\mathrm{SD} \pm 0.22)$ are good estimates of the $\delta{ }^{13} \mathrm{C}$ of the cylinder gas $(-48.46 \%)$. In 
normal practice, the correction would be applied to measurements of unknown samples using the factors derived from standard additions to control base traps.

The principal limitations of the $\mathrm{SrCO}_{3}$ trapping method are a relatively high mass requirement for sample $\mathrm{C}(>200 \mu \mathrm{g} \mathrm{C})$ and the need for correction of data for contamination of the carbonate. These limitations make the method most suitable for experiments in which relatively large amounts $(>1 \mathrm{mg} \mathrm{C})$ of $\mathrm{CO}_{2}$ are trapped, typical examples are long-term laboratory incubations of soils in closed containers, such as canning jars and field soil respiration studies using embedded chambers. All reasonable efforts to minimize the mass of contaminant $C$ should be made since correction errors due to variation in contamination between samples are minimized when the mass of sample $C$ is large compared to the mass of contaminant $\mathrm{C}$. These include the preparation and protection of $\mathrm{CO}_{3}{ }^{2-}$-free $\mathrm{NaOH}$ (Belcher and Nutten, 1960), the use of gas-tight caps on base trap vials after removal from the incubation and flushing of the headspace of the titration vial with $\mathrm{CO}_{2}$-free air. We recommend that a series of control standard additions of $\mathrm{CO}_{2}$ be included in all experiments to allow correction for contamination.

\section{CONCLUSIONS}

Trapping and precipitation of ${ }^{13} \mathrm{CO}_{2}$ as $\mathrm{SrCO}_{3}$ followed by thermal decomposition in an ANCA and CFIRMS can be used to study the ${ }^{13} \mathrm{C}$ content of respired $\mathrm{CO}_{2}$. The use controls with standard additions to correct for contamination is an essential requirement which applies also to gaseous samples. We have shown that $\mathrm{CaCO}_{3}$ decomposes readily in the $\mathrm{ANCA}$, but difficulties in the titration of the $\mathrm{Ca}$ system may preclude its use as a $\mathrm{CO}_{2}$ vector. The $\mathrm{Ba}$ system has the advantage that $\mathrm{Ba}(\mathrm{OH})_{2}$ is much more soluble than the other hydroxides but $\mathrm{BaCO}_{3}$ does not decompose readily in the ANCA. The Sr system is preferred because it works well in the precipitation of $\mathrm{CO}_{3}$ and in the titration of excess $\mathrm{OH}$; finally, $\mathrm{SrCO}_{3}$ decomposes quantitatively in the ANCA, particularly when $\mathrm{V}_{2} \mathrm{O}_{5}$ is included in the sample package.

\section{ACKNOWLEDGMENTS}

This work was funded in part from the Kellog Biological Station Long-Term Ecological Research (LTER) project 'Organisms in the Agricultural Landscape' (National Science Foundation Grant DEB 92-22771 to Michigan State University). We thank Andrew Barrie of Europa Scientific for advice during the design of these experiments.

\section{REFERENCES}

Agren, G.I., Bosatta, E., and J. Balesdent. 1996. Isotope discrimination during decomposition of organic matter: A theoretical analysis. Soil Sci. Soc. Am. J. 60:11211126. 
Balesdent J. and M. Balabane. 1992. Maize root-derived soil organic carbon estimated by natural ${ }^{13} \mathrm{C}$ abundance. Soil Biol. Biochem. 24:97-101.

Balesdent, J., C. Giradin, and A. Mariotti. 1993. Site-related $\delta{ }^{13} \mathrm{C}$ of tree leaves and soil organic matter in a temperate forest. Ecology 74:1713-1721.

Balesdent, J., G.H. Wagner, and A. Mariotti. 1988. Soil organic matter turnover in longterm field experiments as revealed by carbon-13 natural abundance. Soil Sci. Soc. Am. J. 52:118-124.

Barrie, A. and S.J. Prosser. 1996. Automated analysis of light-element stable isotopes by isotope ratio mass spectrometry, pp 1-46. In: T.W. Boutton and S. Yamasaki (eds.), Mass Spectrometry of Soils. Marcel Dekker, Inc., New York, NY.

Belcher, R. and A.J. Nutten. 1960. Quantitative Inorganic Analysis, pp. 182-184. 2nd ed. Butterworths, London, England.

Bonde, T.A., B.T. Christensen, and C.C. Cerri. 1992. Dynamics of soil organic matter as reflected by ${ }^{13} \mathrm{C}$ abundance in particle size fractions of forested and cultivated oxisols. Soil Biol. Biochem. 24:275-277.

Boutton, T.W. 1991. Stable carbon isotope ratios of natural materials: 1. Sample preparation and mass spectrometric analysis, pp. 155-171. In: D.C. Coleman and B. Fry (eds.), Carbon Isotope Techniques. Academic Press, San Diego, CA.

Brooks, P.D., D.J. Herman, G.J. Atkins, S.J. Prosser, and A. Barrie. 1993. Rapid, isotopic analysis of selected soil gases at atmospheric concentrations, pp. 193-202. In: D.E. Ralston, L.A. Harper, A.R. Mosier, and J.M. Duxbury (eds.), Agricultural Ecosystem Effects on Trace Gases and Global Climate Change. ASA Spec. Publ. No. 55. American Society of Agronomy, Madison, WI.

Kirsten, W.J. 1983. Organic Elemental Analysis. Academic Press, New York, NY.

Ryan, M.C. and R. Aravena. 1994. Combining ${ }^{13} \mathrm{C}$ natural abundance and fumigationextraction methods to investigate soil microbial biomass turnover. Soil Biol. Biochem. 26:1583-1585.

Weast, R.C. 1973. CRC Handbook of Chemistry and Physics. 54th ed. CRC Press, Cleveland, $\mathrm{OH}$.

Wedin, D.A., L.L. Tiezen, B. Dewey, and J. Pastor. 1995. Carbon isotope dynamics during grass decomposition and soil organic matter formation. Ecology 76:1383-1392.

Zibilske, L.M. 1994. Carbon mineralization, pp. 835-863. In: R.W. Weaver, S. Angle, P. Bottomley, D. Bezdicek, S. Smith, A. Tabatabai, and A. Wollum (eds.), Methods of Soil Analysis. Part 2. Microbiological and Biochemical Properties. Soil Science Society of America, Madison, WI. 